\title{
M.S. III. Yüzyıl Roma-Sasani İhtilaflarına İlişkin Bir Değerlendirme: Pers Kralı I. Şapur'un Roma İmparatoru Valerianus'u Esir Alması
}

\author{
An Assessment of the Third Century Roman-Sassanid Rivalry and Conflict: \\ The capture of the Roman Emperor Valerian by the Persian King Shapur I
}

\section{Emine BİLGíÇ*}

Özet: Bu makale, İmparator Valerianus'un M.S. 260 yılındaki Edessa Savaşı’nda Sasani Hükümdarı I. Şapur tarafından esir alınmasını konu edinmektedir. Çalışmanın giriş kısmında Roma'nın Küçük Asya politikası üzerinde durulmuş ve Parthlarla birlikte başlayan doğu sınırı sorunları ele alınmıştır. Roma'nın üçüncü yüzyıl krizine girmesiyle Sasanilerin güçlü bir devlet olarak Romalıların karşısına çıkması ve Roma-Sasani ihtilaflarının başlangıç noktası anlatılmıştır. I. Şapur'un Roma karşısındaki başarıları ve Valerianus'la karşılaşması ele alınarak; bu savaşta imparatorun esir alınışı hakkında farklı bilgiler sunan antik kaynaklar irdelenmiş ve ölüm şekli konusundaki tartışmalar okuyucuya sunulmuştur. Roma İmparatorluk Tarihi'nde ilk kez bir Roma imparatorunun düşman tarafından esir alınmasının her iki tarafta yarattığı durum analiz edilmeye çalışılmıştır; zira batılı kaynakların çoğu bu durumu ya göz ardı etmekte ya da Şapur'un zaferinin hile yoluyla alındığını öne sürmekteyken; doğulu kaynaklar Valerianus'un komutanlarıyla birlikte esir alındığını kaydetmektedir. Bu karşılaşma, sonraki dönemde meydana gelen Galerius ile Narses mücadelesini hatırlatmaktadır. Galerius da I. Şapur'un zafer rölyeflerine karşılık olarak Narses'e karşı elde ettiği zaferini Thessalonike'de ölümsüzleştirmek istemiştir. Şapur'un anıt yazıtı ve savaştan sonra kurmuş olduğu kentlerde Roma mimarisinin kullanılması, Edessa'daki savaştan sonra Valerianus yanında çok sayıda Romalı askerin esir alındığını göstermektedir.

Anahtar Sözcükler: Roma, Sasaniler, Şapur, Valerianus, esir alınma

Abstract: This article concerns the capture of the Roman Emperor Valerian at the Battle of Edessa in 260 A.D., by Shapur I, ruler of the Sassanid Empire. The introduction focuses upon the policy of Rome in Asia Minor and Rome's handling of issues concerning its eastern boundary starting with the Parthians. As Rome entered the $3^{\text {rd }}$ c. crisis, the Sassanids became a strong state facing Rome, the starting point for rivalries and conflicts between Romans and Sasanians. In examining the achievements of Shapur against Rome and his encounter with Valerian; the ancient sources, which provide conflicting information concerning the capture of the emperor in this battle were scrutinized and the reader is presented with the debate concerning his death. In Roman Imperial history it was the first time a Roman emperor had been taken prisoner by the enemy and an attempt is made to analyze the situation on both sides after this captivity; while most western sources undervalued this situation, or have asserted Shapur I gained victory through a trick, eastern sources record Valerian was taken captive with his commanders. The encounter between Narses and Galerius in the following period recalls this struggle between Shapur and Valerian. Galerius wished to immortalize his triumph against Narses in Thessalonike, as a response to the victory reliefs of Shapur I. The monumental inscription of Shapur and the cities which were established after the battle employing Roman architectural forms indicate many Roman soldiers were taken prisoner, in addition to Emperor Valerian, after the Battle of Edessa.

Keywords: Rome, Sassanids, Shapur, Valerian, captivity

\footnotetext{
* PhD., Akdeniz Üniversitesi, Edebiyat Fakültesi, Eskiçağ Dilleri ve Kültürleri Bölümü, emineblgc@windowslive.com
} 
Roma'nın Küçük Asya ve dolayısıyla doğuyla olan ilişkileri somut olarak M.Ö. 133 yılında Pergamon Kralı III. Attalos Philomator'un (M.Ö. 139-133), altı yıllık kısa saltanatı sonrasında hastalanıp (?) ölmesinin ardından geride şaibeli bir vasiyet bırakmasıyla başlamıştır (Sall. Hist. IV. 69. 8; krş. Virgilio, 1993; Arslan 2007, 68-69). Buna göre Attalos krallık merkezi olan Pergamon dışındaki topraklarını Roma'ya bırakmıştır (Strab. XIII. 4. 2 c. 624; Liv. perioch. 5859; Vell. II. 4. 1; Val. Max. V. 2 ext. 3; Plin. Nat. XXXIII. 53 [148] b; Plut. Tib. Gracch. XIV. 1; Flor. epit. I. 35. 2; Iust. XXXVI. 4. 5; Eutr. IV. 18; Oros. Hist. V. 8. 4; Fest. Brev. X. str. 46). Böylece Roma M.Ö. 129 yılında Küçük Asya'daki ilk eyaleti olan provincia Asya'y1 kurmuştur (Strab. XIV. 1. 38 c. 646; Liv. perioch. 59; Iust. XXXVI. 4. 6-11; Eutr. IV. 20. 1; Oros. Hist. V. 10. 2). Roma'nın M. Ö. II. yüzyıldan itibaren Hellenistik krallıkları birer birer ele geçirmesi sonunda Roma ile Karadeniz Kralı Mithradates VI Eupator'u (M.Ö.121/120-63) karşı karşıya getirmiş ve M.Ö. 89-63 yılları arasında Roma için zorlu mücadelelerin yaşanmasina neden olmuştur (Arslan, 2007). Roma, Mithradates ile söz konusu çetin savaşlara girişmeden önce Parthları yanına çekmek ya da en azından savaşta onların tarafsız kalmalarını sağlamak amaciyla M.Ö. 95 yılında generalleri Sulla aracıllı̆ıyla Parth elçileriyle görüşmüş (Plut. Sul. 5. 8) ve iki imparatorluk arasında Euphrates (Fırat) sınır olarak kabul edilmiştir. Erken imparatorluk dönemi yazarlarının Parth Krallığı ve Roma İmparatorluğu için "güneşin altındaki en büyük iki egemenlik" (Ioseph. Ant. Iud. XVIII. 46 ) ve "en büyük güçler" (Tac. Ann. II. 56) tanımlamaları yaptığı görülmektedir (Parthlar hakkında genel olarak bkz. Bivar, 1983, 21-97). Fakat iki imparatorluk arasında dostane başlayan ilişkiler, Mithradates'in intihar etmesi ve Mithradates Hanedanlığı'nın Romalılar tarafından ilhak edilmesinden sonra zamanla yerini savaşlara bırakmıştır. M.Ö. 53 yılında Romalı ünlü general Marcus Licinius Crassus (M.Ö. 115-53) önderliğinde Carrhae'da (Harran) yapılan savaşta Roma ordusu ağır bir yenilgi almış ve Crassus öldürülmüştür (Plut. Crass. XVIII-XXXIII; Cass. Dio XL.16-27). M.Ö. 40-33 yılları arasında Romalı devlet adamı ve doğu komutanı Marcus Antonius, Parthlara karşı başarısız bir sefer yapmış (Plut. Anton. XXXII-XXXIII; Huzar, 1978, 173-185; Schieber, 1979, 105-24; Hersh, 1980, 41-5), bunun ardından imparator Augustus (M.Ö. 27-M.S. 14), barışç11 bir dış politikaya yönelmiş ve M.Ö. 20 yılında iki imparatorluk arasında Euphrates'in sınır kabul edildiği bir foedus (anlaşma) yapmıştır (Strab. XVI. I. 28). Pax Romana denilen bu dönemin M.Ö. I. yüzyıldaki Roma İç Savaşı'nın bitmesiyle başladığı ve İmparator Marcus Aurelius'un (M.S. 161-180) ya da oğlu Commodus'un (M.S. 180-192) ölümüyle sonlandığ1 kabul edilir. Roma İmparatoru Augustus, sınırsız bir imparatorluğu "imperium sine fine" (Verg. Aen. I. 279) vurgulamış; ancak imparatorluğun mevcut sınırları içinde intra terminos imperii bir politika amaçlayarak Euphrates'in yukarı kısımlarını fethetme yoluna gitmemiştir.

Roma ile Parthlar arasındaki sınır, M.S. II. yüzyıla kadar Euphrates olarak kalmışken, Traianus'un (M.S. 98-117) başa geçip imparatorluğun sınırlarını genişletmek istemesiyle değişikliğe uğramış ve Euphrates ile Tigris'in (Dicle) doğusuna geçmiştir. Cassius Dio (LXVIII. 17. 1), Traianus'un asıl amacının imparatorluğunun topraklarını İskender'in sınırlarına ulaştırmak olduğunu söyler. Fakat imparator bu amacına ulaşamamıştır; zira M.S. 117 yılında cephenin gerisinde büyük bir isyan çıkmış ve ardından ordu Hatra'da (Irak'ta al-Hadr kenti) ağır bir yenilgiye uğramış; imparator da aynı yılın Ağustos ayında Roma'ya dönüş yolculuğu sırasında Kilikia'dayken Selinus'ta ölmüştür (Cass. Dio LXVIII. 33. 2-3). Ard11ı Hadrianus (M.S. 117-138) da adoptif babası tarafından fethedilen topraklardan vazgeçmiș ve imparatorluğun sınırları tekrardan Euphrates'in batısına çekilmiştir. Hadrianus, imparatorluğu senatus tarafindan onaylandıktan hemen sonra Parth Kralı I. Osroes ile antlaşma yapmış (Aur. Vic. XIV. 1) ve Traianus'un Euphrates ile Tigris'in doğusunda işgal ettiği yerlerden geri çekilmiştir (SHA. Hadrian. V. 3; IX. 1; XXI. 12; Eutr. VIII. 6. 2). İmparator Septimius Severus Dönemi'nde (M.S.193-211) Roma-Parth ilişkileri yeniden gerilmiş, M.S. 197 y1lında Parthlar Nisibis'i (Nusaybin) kuşatma altına alınca imparator doğu seferi düzenlemiş ve bu dönemde 
Legio I, II, III Parthica adıyla üç yeni lejyon oluşturmuş, bunlardan yalnızca Legio II Parthica'yı İtalya'da bırakarak diğerlerini Mesopotamya'ya yerleştirmiştir (SHA Sep. Sev. XVXVI; Millar, 1993, 111-126; Potter, 2004, 133 vd.; Kaya, 2008, 219 vdd).

Severus'un doğu politikası Parth Krallığı'nda bölgesel isyanların artmasında ve Sasanilerin ortaya çıkmasında etkili bir rol oynamıştır. Bölgesel isyanların en önemlisi M.S. 204/205 yılında Fars eyaletinde yerel bir yönetici olan Papak (Papag) tarafından çıkarılmıştır. Parth Kralı IV. Artabanus (M.S. 216-224) ile kardeşi VI. Vologases arasındaki hanedanlık mücadelesinin yarattığ 1 kargaşa ortamından faydalanan Papak, Persis topraklarındaki nüfusunu artırmayı başarmıştır (Potter, 2004, 217-26; Daryee, 2009, 2 vdd.). M.S. 220 civarındaki ölümünden sonra oğlu I. Ardaşır da Pers İmparatorluğu'nu yeniden kurmak için ayaklamış ve etrafindaki askerleri kendi tarafına çekmeyi başarmıştır. Parth Kralı IV. Artabanus ile üç kez karşı karşıya gelen Ardaşır, M.S. 224 yılında yaklaşık 400 sene süren Parth İmparatorluğu'na son vermiş ve Sasani Krallı̆̆g'’nı kurmuştur (Cass. Dio LXXX. 3. 1-2; Herodian. VI. II. 7; Agath. IV. 24. 1).

Kendilerini Pers Krallı̆̆ı'nın varisi olarak gören Sasaniler, Makedonya Kralı Büyük İskender (M.Ö. 336-323) tarafından M.Ö. 330 yılında yıkılan Perslerin topraklarını yeniden fethetmek ve söz konusu dönemin ihtişamını geri getirmek istemişlerdir. I. Ardaşır'ın bu amaç doğrultusunda bir zamanlar Perslerin Ionia ve Karia'yı da içine alan bütün Asya'da hüküm sürdükleri toprakları Roma'dan geri istemesi ve politikayla alamadığını kılıçla alma yoluna gitmesi Roma-Sasani ihtilaflarının ana nedenini oluşturmaktadır (Sasanilerin siyasi tarihi için bkz. Frye, 1983, 2008; ayrıca M.S. 226-363 Roma-Sasani ilişkilerine genel olarak bkz. Dodgeon, \& Lieu, 2005; Kaçar, 2008, 1-22). Dignas ve Winter (2007, 55), IX. yüzyılda yaşamış olan Arap Tarihçi Ebu Cafer Taberi'nin son Akhamenid Hükümdarı III. Darius'un (M.Ö. 338/9-330) intikamını almak için Ardaşır'ın bir isyan başlattığını ve ülkeyi atalarının hükümranlığındaki gibi düzenlemeyi ve meşru ailesine tekrar güç kazandırmayı tasarladığını belirtmesine değinirler.

I. Ardaşır, söz konusu istekleri dolayısıyla M.S. 230-233 yılları arasında Roma İmparatoru Alexander Severus (M.S. 222-235) ile karşı karşıya gelmiştir. Herodianus'a göre (VI. 5. 1-6. 6) ne Persler (Sasaniler, Roma antik kaynaklarında Persler ya da Parthlar olarak aktarılmaktadır) ne de Romalılar bu savaştan herhangi bir üstünlük elde etmiştir. Persler sadece hayatta kalan insan sayısı bakımından üstün gibi görünmekteydiler. Ancak birçok kaynak Alexander Severus'un Roma'ya zaferle dönüşünden bahsetmektedir (Aur. Vict. XXIV. 2; Fest. Brev. XXII; Eutr. VIII. 23; SHA Sev. Alex. 55. 1-3; Oros. Hist. VII. 18. 7; Syncell. 673.17-674. 8; Ced. Comp. Hist. 450.3-7; Zon. III. 122. 7-16). Ancak M.S. 235 y1lında Alexander Severus'un öldürülmesi Roma'yı III. yüzyıl krizi ya da askeri anarşi olarak adlandırılan bir dönemin içine sürüklemiştir. Çünkü Alexander Severus'un öldürülmesiyle kimin imparator olacağına askerler karar vermeye başlamış; böylece Roma iç dünyasında kargaşa ve kaos ortamı meydana gelmiştir. M.S. 235-284 yıllarını kapsayan bu elli yıllık süreç devlet idaresinden askeri yapıya, ekonomiden düşünce sistemine kadar bütün Roma yaşam biçiminin çöküşüne tanıklık etmiştir. $\mathrm{Bu}$ dönemde Roma İmparatorluğu dış istilalar, iç savaşlar ve kontrolden çıkmış ekonomi dolayısıyla neredeyse yıkılmanın eşiğine gelmiştir (Alföldi, 1939, 165-231; Calu, 1969; 1975, 594-613; Crawford, 1975, 560-93; Watson, 2003, 1-21).

Roma'da yaşanan gerileme ve kaosa karşın bu dönemde Sasanilerin yükselişe geçtiği görülmektedir. I. Ardaşır'ın on altı yıllık hükümdarlığından sonra oğlu I. Şapur (M.S. 240/241272) başa geçmiş ve babasının Roma'ya karşı giriştiği mücadeleyi kaldığı yerden devam ettirerek, tahtta kaldığı süre içerisinde Roma İmparatorları III. Gordianus (M.S. 244), Arap kökenli Philippus (M.S. 244-252) ve Valerianus (M.S. 252/253-260) ile karşı karşıya gelmiştir. I. Şapur dönemi Sasanilerin en parlak dönemlerinden biri olmuştur. III. Gordianus M.S. 243 y1linda Resaina'da (Mesopotamya eyaletinde bir kent) vuku bulan ilk savaşta praetor praefectus'u Timesitheus sayesinde zafer kazansa da (Amm. Marc. XXIII. V. 17); Timesitheus'un ölümü 
üzerine M.S. 244 dolaylarında Misik'te (Irak'ta bugünkü Felluce kenti) yapılan savaş1 kaybetmiştir (Kaya, 2005, 157-167; Dignas, \& Winter, 2007, 78 vdd.). İmparator Gordianus'un Misik Savaşı'ndan sonraki ölümü hakkında üç anlatı bulunmaktadır: İmparator ya savaşta ölmüş (ŠKKZ str. 6-9) ya kendisinden sonra imparator olan Philippus'un ihaneti dolayısıyla öldürülmüş (Aur. Vict. 27. 8; Fest. Brev. XXII. str. 2-7; Eutr. IX. 2. 2-3; Amm. Marc. XXIII. V. 17; SHA Gord. XXX. 1-9; Oros. Hist. VII. 19. 5; Zos. I. 17. 2-19) ya da savaş sırasında attan düşerek kalçasına aldığı darbe sonucu yaşamını yitirmiștir (Ced. Comp. Hist. I. 451. 11-12; Zon. III. 128. 8-17; ayrica bkz. Oost, 1958, 106-7; Winter, 1988, 83-97; Bleckmann, 1992, 66-78; Schottky, 1994, 232-5; Körner, 2002, 77-92). Gordianus'un ölümünün ardından başa geçen Arap Philippus, biran önce Roma'ya dönmek ve iktidarını sağlamlaştırmak adına Şapur ile M.S. 244 yılında sözlü bir anlaşma yapmıştır (Evagr. Hist. eccl. V. 7; Zos. III. 32. 4; Zon. III. 130. 22-7). Bu anlaşmaya göre Gordianus tarafından kazanılan Nisibis ve Carrhae yeniden Pers idaresi altına girmiş ve Roma'nın Armenia üzerindeki etkisi azaltılmıştır (Dignas, \&Winter, 2007, 119-121). Fakat Philippus ile yapılan barış uzun sürmemiştir. M.S. 249 yılında patlak veren iç savaş sırasında Philippus, İtalya'nın Verona kentinde yapılan savaşı kaybetmiş ve Decius (M.S. 249-252) imparator ilan edilmiştir.

İmparator Decius'un doğudan ziyade batıda Gotlar ile mücadele etmek zorunda kalması (Kulikowski, 2007), Sasanilerin daha rahat hareket etmesine olanak sağlamıştır. Bu dönemde I. Şapur Armenia'ya yönelmiş ve M.S. 252 yılında bu ülkeyi doğrudan kendi kontrolüne alarak Armenia Kralı II. Arsakid'i (II. Hüsrev) öldürmüştür (Zon. III. 137. 2-6). Hüsrev'in halefi Tiridates Roma'ya kaçmış; Şapur ise büyük oğlu Hormizd Ardaşır'1 (I. Hürmüz olarak da geçer - M.S. 252-3?) Armenia'nın büyük kralı olarak atamıştır (Schottky, 1994, 223-25; III. yüzyılda vuku bulan Armenia üzerindeki Roma-Sasani Savaşları hakkında bkz. Chaumont, 1969, 1976). Armenia'nın ele geçirilmesinin ardından M.S. 252/253 yılında Barbalissos'ta (Qual'at Balis) 60.000 kişilik bir Roma ordusuyla savaşa girişen Şapur büyük bir zafer kazanmışıtır (ŠKZ str. 10-19). Nakş-i Rüstem'deki Kâbe-i Zerdüşt Anıtı'nda Şapur'un faaliyetlerini kayda alan üç dilli yazıttan (Persce-Partca-Hellence), kralın Syria'yı istila edip eyaletin önemli kentleri Antiokheia (Antakya), Hierapolis (Menbij), Sura (al-Hammam yakınında), Beroea (Halep), Zeugma (Belkıs), Dura Europos, Doliche (Dülük) ve diğer bazı kentleri, ayrıca Kappadokia'dan Satala (Sadak) ve Domana gibi kentler ile birlikte toplam 37 kenti ele geçirdiği öğrenilmektedir (Syria'nın işgali için bkz. Orac. Siby. XIII. 108-30; Mesopotamya ve Küçük Asya'nın işgali için bkz. Zos. I. 27. 2; III. 32. 5; Antiokheia'nın kent yöneticilerinden Mariades adında birinin ihaneti yüzünden I. Şapur'un eline geçmesi hakkında bkz. Orac. Siby. XIII. 89-102; SHA trig. tyr. 2; Kâbe-i Zerdüşt yazıtının yorumlanması hakkında ayrıca bkz. Heidemarie, 2010, 205222). Syria'da pek çok kenti ele geçiren Şapur Emesa'ya (Humus) geldiğinde kent halkı güçlü bir direniş göstermiş (Orac. Siby. XIII. 147-54; Emesalıların Şapur üzerinde zafer kazanması ile ilgili bkz. IGLS 1799-1800-1801); özellikle Uranius Antoninus Sampsigeramus isimli kentin piskoposu başarılı bir mücadele göstermiş, hatta kendisini imparator ilan edebilecek kadar ileri gitmiştir (Malal. chron. 296. 10-297. 20).

Sasaniler, I. Şapur önderliğinde Asya'ya doğru ilerlemekteyken Roma'da İmparator Decius'un Goth seferi sırasında ölmesinin ardından M.S. 251 yılında Moesia Eyaleti Valisi C. Vibius Trebonianus Gallus (M.S. 251-3) imparator ilan edilmiş, ancak Gallus ne Sasanilerin ne de Gothların saldırılarına zamanında müdahele etmiștir. Bundan dolayı diğer Moesia Valisi Aemilianus askerler tarafından imparator ilan edilmiş ve Gallus ile Aemilianus arasında bir iç savaş meydana gelmiştir. Söz konusu çekişmeden Aemilianus zaferle ayrılmış ve Gallus M.S. 253 y1lında öldürülmüştür (Eutr. IX. 5. 1-4). Gallus'un ölümü üzerine aynı yıl Raetia'da Publius Licinius Valerianus, Roma İmparatoru ilan edilmiştir. Valerianus ve Aemilianus arasında savaş kaçınılmaz olmuş; fakat iki ordu karşı karşıya geldiğinde Aemilianus'un askerleri savaşmaktan 
ziyade kendi imparatorlarını öldürmeyi tercih etmişlerdir (Syncel. Chron. 465. 22-25; Zon. III. 138. 15-139. 3). Böylece Valerianus savaşmaksızın imparator olmuştur (Potter, 2004, 252). İmparator olmadan önceki askeri kariyerinde oldukça yetenekli bir komutan olarak başarılar kazanmış olan Valerianus, Alexander Severus döneminde consul'lük yapmış olmasının yanı sıra soy bakımından Romalı olmasıyla da uzun zamandır beklenen bir imparator olmuştur (Syme, 1971, 215; Brauer, 1975, 68 vd.). Yaklaşık olarak altmış yaşlarında olan imparator oğlunu da Augustus ilan ederek yönetime ortak etmiştir. Valerianus (M.S. 253-260) ve oğlu Gallienus (M.S. 253-268) başa geçtikleri sırada imparatorluk hem kuzeyden hem de doğudan gelen saldırılar nedeniyle savaş halinde bulunuyordu. Ayrıca bu dönemde savaşların uzun süreli olmasından dolayı tarımsal faaliyetler durma noktasına gelmiş; kıtlık baş göstermiş ve veba salgını ortaya çıkarak birçok kişinin ölümüne neden olmuştur (Zos. I. 36. 1. 6-8).

Valerianus, oğlu Gallienus’u batıda bırakıp doğu komutasını kendisi alarak önceki imparatorların başarısızlıklarını unutturacak bir başarı elde etmek üzere Antiokheia'ya (Antakya) hareket etmiştir (Zos. I. 30. 1). M.S. 256 yılında Antiokheia'ya gelen imparator M.S. 259/260 yılında I. Şapur ile Carrhae ve Edessa (Urfa) arasında bir yerde vuku bulan savaşta karşı karşıya gelmiştir. Kâbe-i Zerdüşt yazıtından Valerianus'un 70.000 kişiden oluşan ordusunda Roma İmparatorluğu'nun her ulusundan birlikler bulunduğu öğrenilmektedir (ŠKZ str. 19-25: Germania, Raetia, Noricum, Dacia, Pannonia, Moesia, Istria, Hispania, Mauritania, Thrakia, Bithynia, Asya, Pamphylia, Isauria, Galatia, Lykia, Kilikia, Kappadokia, Phrygia, Syria, Phoenikia, Arabia, Lydia ve Mesopotamya). I. Şapur'un

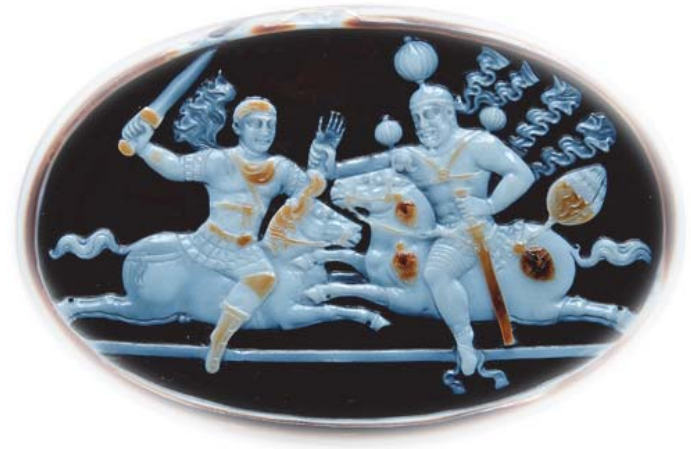

Fig. 1. Şapur'un Valerianus'u ele geçirmesini sahneleyen cameo'su Edessa'yı kuşatması üzerine Valerianus başta çarpışmaya girmeye tereddüt etmiş ancak askerlerinin başarılı savunması karşısında cesaretlenerek savaşa katılmıştır (Zon. III. 140. 5-12). Fakat savaş sonunda Roma ordusu büyük bir hezimete uğramış; başta Valerianus olmak üzere Roma komutanları, senatörleri ve Roma kuvvetinde subay olarak her kim varsa I. Şapur tarafından esir alınmıştır (ŠKZ str. 25-30).

V. yüzyıl pagan tarihçilerinden Zosimus'un (I. 36. 1-2) aktarımına göre, Valerianus ümitsizliğe kapılmış ve Pers Kralı Şapur’a para teklifinde bulunarak savaşı sonlandırmak istemiștir. Ancak Şapur, Valerianus ile yüzyüze görüşmek istediğini belirterek imparatoru ayağına çağırtmıştır. Kralın bu isteğini tedbirsizce kabul eden Valerianus görüşmeye gidince Şapur tarafından esir alınmıştır (Aur. Vict. 32. 5). IX. yüzyıl yazarı Georgius Syncellus (466. 815) ise, Edessa'da iken ordusunda kıtlık baş göstermesi dolayısıyla öfkelenen askerlerinden korkan Valerianus'un Şapur’a gönüllü olarak teslim olduğunu söyler.

Orosius (VII. 24), Valerianus'un yaşadığı sürece köle hizmetine mahkûm edildiğini, hatta Şapur atına binmek istediği zaman kralı eliyle değil sırtıyla kaldırmak için yere eğildiğini bildirir (Valerianus'un Edessa savaşı sonrasında esir alınması ve yaşamının kalan günlerini Persler arasında bir köle olarak geçirmesi hakkında ayrıca krş. Eus. Eccl. Hist. VII. 13. 1-6; Fest. Brev. XXIII. str. 8-13; Eutr. IX. 7; Epitome de caesaribus 32. 5-6; Oros. Hist. VII. 22. 3-4; Petr. Pat. frag. 9; Agath. IV. 23. 7-8; Iord. Hist. Rom. 287). Lactantius (V), Eusebius Hieronymus (Chron. 220.12-19), Orosius (Hist. VII. 22. 3-4), Iordanes (His. Rom. 287) gibi bazı kaynaklar Valerianus'un esarete düşmesini, Hristiyanlara kovuşturma yaptığı ve dolayısıyla onların tanrısına saygısızlık ettiği için tanrı tarafından böyle cezalandırıldığı yönünde yorumlamaktadır. Zira Valerianus’un kısa süren imparatorluğuna rağmen Hristiyanlara karşı zalim 
olduğu ve işkenceler yaptığı bilinmektedir (Valerianus'un döneminde yapılan kovuşturmalar için ayrıca bkz. Clarke, 2008, 637-647). Fakat imparatorun ölümü ile ilgili henüz kesin bir bilgi yoktur. Hristiyan yazar Lactantius (V), imparatorun sonraki y1llarda derisinin yüzülüp al bir renge boyanarak Pers tapınağına asıldığını ve bunun Romalılara bir ihtar olarak hep hatırlatıldığını aktarır (ayrıca bkz. Reiner, 2006, 325-29). Aurelius Victor (32. 5) ise Valerianus'un yaşlı bir adam olarak hala kuvvetliyken imparatorluğunun altıncı yılında öldürülmek üzere aşağılayıcı bir şekilde derisinin yüzüldüğünü söyler. Buradaki tarihi kabul edersek imparator M.S. 259/260 yılında, esir alındıktan hemen sonra hayatını kaybetmiştir. Dignas ve Winter $(2007,80)$ imparatorun esaret içindeyken ölmüş olması gerektiğini belirtirken tarihi konusunda bilgi vermemektedirler. Bununla beraber Sasaniler Batı'ya karşı kazandıkları en büyük zaferlerden biri olan bu zaferi kutlamış olmalıdırlar. Burada dikkat çeken bir diğer konu ise oğlu Gallienus'un ya da Roma'nın, imparatoru geri almak için herhangi bir çaba göstermemesidir. Ne antik kaynaklar ne de epigrafik belgeler bu konu ile ilgili bilgi vermemektedir.

İmparator Şapur diğer uluslarla söz konusu savaşın neticesi ile ilgili mektuplaşmıştır. Bunlardan biri Hazar Denizi'nin güney batı kıyısındaki dağlık bölgede yaşayan Cadusiilerin Kralı Velenus'un, I. Şapur'u zaferinden ötürü kutladığını, ancak Valerianus'un kendi ulusuna geri verildiği takdirde onları daha çok tebrik edeceğini ve Romalıların hiçbir zaman yenildikleri zamandan daha tehlikeli olmadıklarını, bu yüzden Valerianus'u geri vererek Romalılarla barış yapmalarının kendileri için de faydalı olacağını söyleyen mektubudur (SHA Valerian II). Diğerinde ise Armenia Kralı Artavasdes, Şapur'a yaşlı bir adamı yakaladıklarını; ancak dünyanın bütün uluslarını kendilerine düşman ettiklerini iletmektedir (SHA Valerian III). Son olarak ise Şapur'un kendilerine yazmış olduğu mektubu almayı reddeden Baktria, Hiberia ve Albania1ılar, Romalı komutanlara Valerianus'un serbest bırakılması için uğraşacaklarını bildirmişlerdir (SHA Valerian IV). Savaş sonrasında I. Şapur tarafindan Persis'te kurulan Bişapur (Şapur'un güzel kenti) kentinde tespit edilen mozaikli yapılar inşa biçimi bakımından Bişapur'da çalışan işçiler arasında Romalı esirlerin olduğunu kanıtlar niteliktedir (Ghirshman, 1956-71; 1962; 13839; Dignas, \&Winter, 2007, 256 vd.; krş. Canepa, 2009, 75-78).

Söz konusu zaferin ardından I. Şapur muhtemelen ordusunu iki ana kuvvete ayırdıktan sonra neredeyse bütün Kilikia sahilini işgal altına almış; aralarında Zephyrion (Mersin), Tarsus, Korykos (Kizkalesi), Anazarbos/Agrippiada (Anavarza), Kastabala (Bodrumkale), Anemourium (Anamur), Selinus (Selinti), Sebaste (Ayaş), Seleukia (Silifke), Tyana (Kemerhisar) kentleriyle birlikte ayrıca Cappadokia Comana'sı (Şar), Kybistra (Ereğli), Sebastia (Sivas), Birtha (Madenşehir), Laranda (Karaman) ve Ikonium (Konya) kentleriyle birlikte toplam 36 kenti zapt etmiştir (ŠKKZ str. 30-37). Kazanılan başarının coşkusuyla kentleri yağmalamaya girişen ordu Şapur'un Asya'yı tüm olarak ele geçirme firsatını ortadan kaldırmıştır. Zira zafer sarhoşu olan Persler kendilerini kaybetmiş olduklarından Valerianus'un oğlu İmparator Gallienus'un

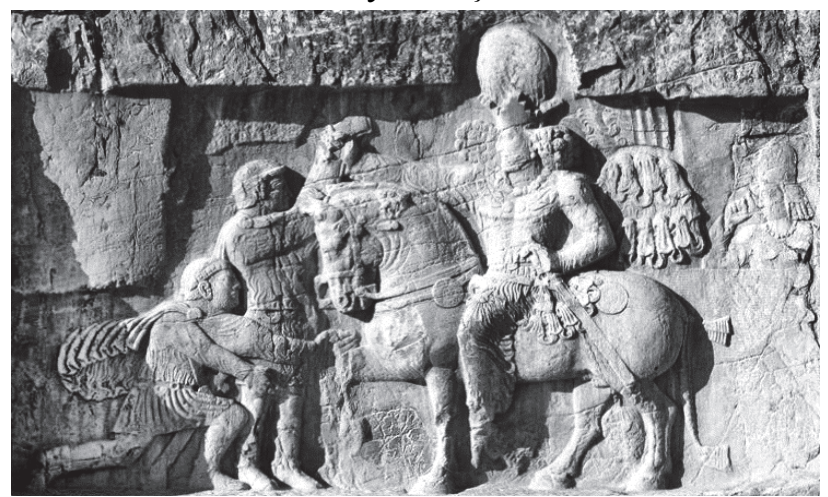

Fig. 2. I. Şapur'un Roma’ya karşı zaferinin betimlenmesi
Doğu'nun Komutanı olarak atadığı Palmyra Kralı Odaenathus tarafindan yenilgiye uğratılmışlar ve Syria ile Asya'dan çıkarılmışlardır (Odaenathus'un Persler üzerindeki başarısı için bkz. Fest. Brev. XXIII. str. 13-18; Eutr. IX. 10; SHA Valerian IV. 2-4; SHA Gallien. XII. 1; Oros. Hist. VII. 22. 12; Agath. IV. 24. 4; Dignas, \& Winter, 2007, 158161; ayrica bkz. Chrysos, 1978, 51-2; Swain, 1993, 157-164; Potter, 1996, 271-285). 
Sonuç olarak söz konusu y1llarda Roma, hem kuzeyde Gothlarla hem doğuda Sasanilerle mücadele etmekteyken bunun yanı sıra imparatorluk içinde bir istikrarsızlık söz konusuydu. Sürekli iç ve dış savaşlarla mücadele eden Roma ordusu zayıflamaktayken bir krallıktan imparatorluğa dönüşen Sasaniler ise kurucu I. Ardaşır'ın on altı; oğlu I. Şapur'un yaklaşık otuz yıllık hükümdarlıklarıyla istikrarlı bir şekilde yönetilmekte ve güçlenmekteydiler. Her iki imparatorluğun içinde bulunduğu durum göz önüne alındığında I. Şapur'un durdurulamaz yükselişi ve başarıları dikkate değer görülmektedir. Roma imparatorluk tarihinde ilk kez bir Roma İmparatoru esir alınmış ve düşman topraklarında köle statüsü içinde yaşamış; derisi yüzülmek suretiyle öldürülmüştür (krş. Canepa, 2009, 68-71). Roma dünyas1 yıllar boyu bu utanç verici olayın etkisinde kalmıştır. Şapur ise, Roma imparatorlarına karşı kazandığı zaferlerini herkesin bilmesi, öğrenmesi ve hatırlaması için Firuzabad'daki Nakş-i Rüstem'de bulunan Kâbe-i Zerdüşt adlı anıtın duvarlarına üç dilde kaydetmiştir. Ayrıca Roma'yı küçük düşüren ilgili rölyeflerde söz konusu üç imparatora karşı kazandığı zaferlerini tasvir ederek ölümsüzleştirmiştir (bkz. Macdermot, 1954, 76-80; Gajé, 1965, 343-88; Mackintosh, 1973, 183-203; Hermann, 1980; Meyer, 1990, 237-302; krş. Hermann, 2000, 35-45; Canepa, 2009, 71-75). Bu rölyefler Fars eyaletindeki üç kent arasına yerleştirilmiştir: Darab'da bir, Bişapur'da üç, Nakş-i Rüstem'de bir tane bulunmaktadır. Macdermot, üç Roma imparatorunun betimlendiği Nakş-i Rüstem ve Bişapur'daki rölyeflerde Romalı elbiseleriyle ayırt edilen, ayakta duran ve sakalı bıyığı temiz, traş olmuş figürü esir alınan Valerianus; Şapur'un önünde diz çöker bir vaziyette görünen sakallı figürü Philippus; son olarak Şapur'un ayakları altında ölü bir şekilde betimlenen sakalsız figürü ise III. Gordianus olarak karakterize etmektedir. Ancak Mackintosh, Macdermot'un bu görüşünün herkes tarafından kabul görmediğini belirterek söz konusu rölyeflerdeki ayakta duran ve diz çöken figürlerinin Valerianus ve Philippus olarak betimlenmesinin tartışma konusu olduğunu söylemektedir.

\section{KAYNAKÇA}

Agath. Agathias, Historiae. R. Keydell, Agathiae Myrinaei historiarum libri quinque [Corpus fontium historiae Byzantinae. Series Berolinensis. Berlin. 1967.

Amm. Marc. Ammianus Marcellinus, Rerum Gestarum Libri. Trans. J. C. Rolfe I-III. Cambridge, MassLondon. $2005^{8}$ (The Loeb Classical Library).

Alföldi, A. (1939). "The crisis of the Empire (AD 249-270)". CAH, XII, 165-231.

AMI Archäologische Mitteilungen aus Iran.

ANRW Aufstieg und Niedergang der Römischen Welt.

Arslan, M. (2007). Roma'nın Büyük Düssmanı: Mithradates VI Eupator. İstanbul: Odin Yayıncıllk.

Aur. Vict. Aurelius Victor, liber de caesaribus. Trans. H.W. Bird. Liverpool. 1994.

AJPh American Journal of Philology.

Bivar, A. D. H. (1983).“"The Political History of Iran under the Arsacids". CHI, III. I, 21-99.

Bleckmann, B. (1992). Die Reichskrise des III. Jahrhunderts in der spätantiken und byzantinischen Geschichtsschreibung : Untersuchungen zu den nachdionischen Quellen der Chronik des Johannes Zonaras. Quellen und Forschungen zur Antiken Welt, vol. I. Münih.

Brauer, G. C. (1975). The Age of The Soldier Emperors. Imperial Rome, A. D. 244-284. Park Ridge, New Jersey: Noyes Press.

CAH The Cambridge Ancient History.

Calu, J. P. (1969). La Politique Monétaire des Empereurs Romains de 238 à 311. Paris: De Boccard.

Calu, J. P. (1975). “Approches numismatiques de I'histoire du III e siècle”. ANRW, II. 2, 594-613.

Canepa, M. P. (2009). The Two Eyes of the Earth. Art and Ritual of Kingship Between Rome and Sasanian Iran. Los Angeles - London.

Cass. Dio Cassius Dio, Rhomaika. Trans. E. Carry I-IX. London. 1914-1927 (The Loeb Classical Library).

Ced. Comp. Hist. Georgius Cedrenus, Compendium Historiarum. Ed. I. Bekker. I-II vol. Corpus scriptorum 
historiae Byzantinae. Bonn. 1838-1839.

Chaumont, M. L. (1969). Recherches sur l'histoire d'Arménie de l' avènement des sassanides à la conversion du royaume. Paris.

Chaumont, M. L. (1976). 'L'Arménie entre Rome et l'Iran. De l'avènement d'Auguste à l'avènement de Dioclétian. ANRW, II. 9.I, 71-194.

CHI The Cambridge History of Iran.

Chron. Pasch. Chronicon Paschale. Ed. L. A. Dindorf. Chronicon paschale, vol. I [Corpus scriptorum historiae Byzantinae. Bonn: Weber, 1832].

Chrysos, E. K. (1978). "The title BA $\mathrm{I} \Lambda \mathrm{EY} \Sigma$ in early Byzantine international relations". DOP, 32, 29-75.

Clarke, G. (2008). “Third-century Christianity”. CAH, XII, 637-647.

Crawford, M. (1975). "Finance, Coinage and Money from the Severans to Constantine". ANRW, II. 2, 560-593.

Brauer, G. C. (1975). The age of soldier emperors: Imperial Rome, AD 244-284. New Jersey: Noyes Press.

Bunson, M. (2002). Encyclopedia of the Roman Empire. New York: Facts On File, Inc.

CP Classical Philology.

CQ The Classical Quarterly.

Daryee, T. (2009). Sasanian Persia: The Rise and Fall of an Empire. London; New York: I. B. Tauris \& Co. In association with the Iran Heritage Foundation.

Dignas, B., \& Winter, E. (2007). Rome and Persia in Late Antiqutiy. Neighbours and Rivals. New York: Cambridge University Press.

Dodgeon, M. H., \& Lieu, S. N. C. (2005). The Roman Eastern Frontier and the Persian Wars (226-363 A.D.). London \& New york: Routledge.

DOP Dumbarton Oaks Papers.

Epitome de Caesaribus. Trans. R. Gruendel. Leipzig. 1970.

Eus. Eccl. Hist. Eusebius. Ecclesiastical History. Trans. F. Winkelmann. Berlin. 1975.

Eus. Hier. Chron. Eusebios Hieronymos. Chronicon. Ed. R. Helm. Berlin. 1956.

Eutr. Eutropius. Brevarium ab urbe condita. Trans. H. W. Bird. The Breviarum ab Urbe Condita of Eutropius. Liverpool 1993 (The Loeb Classical Library).

Evagr. Hist. eccl. Evagrius. Historia Ecclesiastica. Ed. J. Bidez \& L. Parmentier The Ecclesiastical History of Evagrius with the Scholia. London: Methuen, 1898 (repr. New York: AMS Press 1979).

Fest. Brev. Rufius Festus. The Breviarium of Festus. Trans. J. W. Eadie. London 1967.

Flor. epit. Annius Florus. L. Annaei Flori Epitoma De Tito Livio Bellorum Omnium Annorum DCC Libri II. Trans. E. S. Foster. Lucius Annaeus Florus The Two Books of the Epitome, Extracted from Titus Livius, of All the Wars of Seven Hundred Years. London, New York 1929 (The Loeb Classical Library).

Frye, R. N. (1983). “The political history of Iran under Sasanians”. CHI, III. I, 116- 80.

Frye, R. N. (2008). “The early Sassanians”. CAH, XII, 464-72.

Gajé, J. (1965). “Comment Sapor a-t-il “triomphé” de Valérien?”. Syria, 42, 343-88.

Georgius Syncellus, Ecloga chronographica. Ed. A. A. Mosshammer. Leipzig: Teubner. 1984.

Gignoux, Ph. (1991). “D’ Abnūn à Māhān. Étude de deux inscriptions sassanides”. StIr, 20, 9-22.

Ghirshman, R. (1956-71). Bichapour I-II. Paris: Geuthner.

Ghirshman, R. (1962). Iran: Parthians and Sassanians. London: Thames and Hunson.

Herodian. Herodianus, Ab Excessu Divi Marci. Ed. K. Stavenhagen. Herodiani ab excessu divi Marci libri octo. Leipzig: Teubner, 1922 (repr. Stuttgart: 1967).

Heidemarie, K. (2010). "Die Felzüge Shapurs d. Gr. (240-271 n. Chr.) Anatolien um die Mitte des 3. Jahrhunderts n. Chr.”. Adalya, XIII, 205-222.

Hermann, G. (1980). The Sasanian Rock Reliefs at Bishapur I: Bishapur III, Triump attributed to Shapur I. Iranische Denkmäler. Reihe III. Lieferung 9. Berlin. 
Hermann, G. (2000). “The rock reliefs of Sasanian Iran". in Mesopotamya and Iran in the Parthian and Sasanian Periods: Rejection and Revival c. 238 BC-AD 642. Proceedings of a Seminar in Memory of V. G. Lukanin. Ed. J. Curtis. London: British Museum.

Hersh, C. A. (1980). “The coinage of Quintus Labienus Parthicus”. SNR, 59, 41-45.

Huzar, E. G. (1978). Mark Antony: A Biography. United States of America: The University Minnesota Press.

IGLS Inscriptions grecques et latins de la Syrie.

Ioseph. Ant. Iud. Flavius Iosephus Historicus, Antiquitates Iudaicae. Trans. H. St. J. Thackeray IV-IX. London, New York 1930-1939 (The Loeb Classical Library).

Iord. Hist. Rom. Iordanes. Historiae Romae. Trans. T. Mommsen. 1882.

Iust. Marcus Iulianus Iustinus, M. Iuliani Iustini Epitoma Historiarum Philippicarum Pompei Trogi. Trans. R. Develin. Atlanta, GA 1994.

JDAI Jahrbuch des Deutschen Archäologischen Instituts.

Jones, A. H. M. (1908). The Roman Empire BC. 29-AD. 476. New York: Kessinger Publishing.

JRS Journal of Roman Studies.

Kaçar, T. (2008). “Anadolu'da Sasaniler ve Romalılar, M.S. 226-363: Emperyal İdeoloji Kriz”. Tarih Dergisi, 47, 1-22.

Kaya, M. A. (2005). "III. Gordianus'un Pers (=Sasani) Seferi: Güzergâh, Savaşlar ve İmparatorun Ölümü”. Tarih Incelemeleri Dergisi, XX. 1, 157-167.

Kaya, M. A. (2008). Septimius Severus: Roma'nın Afrikalı Imparatoru. İstanbul: Arkeoloji ve Sanat Yayınları.

Keaveney, A. (1982). "The king and the war-lords: Roman-Parthian circa 64-53 BC". AJPh, 103, 412-28.

Körner, Ch. (2002). Philippus Arabs. Ein Soldatenkaiser in der Tradition des antoninisch - severischen Prinzipats. Untersuchungen zur antiken Literatur und Geschichte vol. 61. Berlin; New York: De Gruyter.

Kulikowski, M. (2007). Rome's Gothic Wars from the third Century to Alaric. New York: Cambridge University Press.

Lact. Lactantius, de mortibus persecutorum, Ed. J. Creed. 1984. Oxford: Clarendon Press.

Liv. perioch. Livius. Ab urbe condita librorum periochae. Çev.: S. Şenbark (1992-). İstanbul: Arkeoloji ve Sanat Yayınları.

Macdermot, B. C. (1954). "Roman Emperors in the Sassanian Reliefs". JRS, 44, 76-80.

Mackintosh, M. C. (1973). "Roman influences on the victory-relief of Shapur I of Persia". California Studies in Classical Antiquity 6, 181-203.

Malal. chron. Ioannes Malalas, Chronographia. Ed. L. Dindorf. Ioannis Malalae chronographia [Corpus scriptorum historiae Byzantinae. Bonn: Weber, 1831].

Meyer, M. (1990). “Die Felsbilder Shapurs I”. JDAI, 105, 237-302.

Millar, F. (1993). The Roman Near East 31 BC.-AD. 337. United States of America: Harvard University Press.

Oost, S. I. (1958). "The death of the Emperor Gordian III". CP, 53, 106 - 7.

Orac. Siby. Oracula Sibyllina. Ed. J. Geffcken. Die Oracula Sibyllina [Die griechischen christlichen Schriftsteller 8. Leipzig: Hinrichs, 1902], 1-226.

Oros. Hist. Orosius, Historiarum adversus paganos libri VII. Trans. I. W. Raymond. Seven Books of History Against the Pagans. 1936. New York: Columbia University Press.

Peachin, M. (1990). Roman Imperial Titulature and Chronology AD. 235-284. Amsterdam: Gieben.

Petr. Pat. frag. Petrus Patricius FHG IV. Trans. C. Müller. Paris 1868.

Plin. Nat. G. Plinius Secundus "Yaşlı". Naturalis Historia. Trans. H. R. Rackham, vol. I-IV; IX; W. H. S. Jones, vol. VI-VIII; D. E. Eichholz, vol. X. Cambridge, Mass-London. 1938-20048 (The Loeb Classical Library).

Plut. Plutarkhos, Bioi Paralleloi (Crass.=Crassus; Anton.=Marcus Antonius, Sull. $=$ Sulla; Tib. Gracch.= Tiberius Gracchus). Trans. B. Perrin. Plutarch's Lives. Vol. I-XI. London, New York 1959 (The Loeb Classical Library). 
Potter, D. S. (1996). "Palmyra and Rome: Odaenathus' titulature and the use of the imperium maius". ZPE, 113, 271-285.

Potter, D. S. (2004). The Roman Empire at Bay AD. 180-395. London and Newyork: Routledge.

Reiner, E. (2006). "The Reddling of Valerian". CQ, 56. 1, 325-329.

RstorAnt Rivista storica dell'antichità.

Sall. Hist. Sallustius, Historiae. Trans. J. C. Rolfe. New York. 1955 (The Loeb Classical Library).

Schieber, A. S. (1979). "Antony and Parthia”. RstorAnt, 9, 105-124.

Schottky, M. (1994). "Dunkle Punkte in der armenischen Königsliste”. AMI, 27, 223-235.

SEG Supplementum Epigraphicum Graecum.

SHA Scriptores Historiae Augustae $($ Gallien.$=$ Gallieni Duo, Gord.$=$ Gordiani Tres, Hadrian.$=$ De Vita

Hadriani Aelii, Sep. Sev.=Septimius Severus, Sev. Alex.=Severus Alexander, trig. tyr. =tyranni

triginta, Valerian. $=$ Valeriani Duo). Trans. D. Magie $\left(1998^{6}\right)$. London (The Loeb Classical Library).

ŠKZ Inscription of Šāpūr I at the Ka'ba-I Zardušt in Naqšs-1 Rustam.

Southern, P. (2004). The Roman Empire From Severus to Constantine. London and New York: Routledge.

SNR Schweizerische Numismatische Rundschau.

Strab. Strabon. Geographika. Trans. H. L. Jones. London and New York. 1917-1932.

Syme, S. R. (1971). Emperors and Biography: Studies in the Historia Augusta. Oxford: Clarendon Press.

Syncell. Chron. Georgius Syncellus. Ecloga chronographica. Trans. A. A. Mosshammer (1984). Leipzig;

Teubner.

Swain, S. (1993). "Greek into Palmyrene. Odaenath as corrector totius orientis". ZPE, 99, 157-64.

Tac. Ann. Tacitus. Annales. Ed. J. Jackson. Cambridge, Mass-London. 1969 (The Loeb Classical Library).

Val. Max. Valerius Maximus. Facta et dicta memorabilia absoluti, ambusiti, damnati, externi. Trans. D.

Wardle. Memorable Deeds and Saying. Book I. Oxford-New York 1998.

Vell. Velleius Paterculus. Historia Romana. Trans. F. Shipley. London 1924 (The Loeb Classical Library).

Verg. Aen. Vergilius. Aeneas. Çev. İ. Z. Eyuboğlu. İstanbul. 1995: Payel Yayınları.

Virgilio, B. (1993). Gli Attalidi Di Pergamo. Pisa: Giardini.

Watson, A. (2003). Aurelian and Third Century. London \& New York: Routledge.

Winter, E. (1988). Die sāsānidisch-römischen Friedensverträge des 3. Jahrhunderts n. Chr. - Ein Beitrag zum Verständnis der aussenpolitischen Beziehungen zwischen den beiden Grossmächten. Frankfurt.

Zon. Zonaras. Epitome Historiarium, Ed.T. Büttner-Wobst.: Ioannis Zonarae epitomae libri xiii -xviii (Corpus scriptorum historiae Byzantinae. Vol. III), Bonn: Weber. 1897.

Zos. Zosimos. Historia Nova. Trans. R. T. Ridley, Zosimus: New History. Byzantina Australiensia 2. 1984. Sydney: Australian Association for Byzantine Studies.

ZPE Zeitschrift für Papyrologie und Epigraphik. 